\title{
Effect of Firefighting Intervention on Occupant Tenability during a Residential Fire
}

\author{
Steve Kerber* (D) and John W. Regan, Underwriters Laboratories Inc, 6200 Old \\ Dobbin Lane, Suite 150, Columbia, MD 21045, USA \\ Gavin P. Horn, Fire Service Institute, University of Illinois at Urbana- \\ Champaign, 11 Gerty Drive, Champaign, IL 61820, USA \\ Kenneth W. Fent, Division of Surveillance, Hazard Evaluations, and Field \\ Studies, National Institute for Occupational Safety and Health (NIOSH), \\ 1090 Tusculum Ave, Cincinnati, OH 45226, USA \\ Denise L. Smith, Fire Service Institute, University of Illinois at Urbana- \\ Champaign, 11 Gerty Drive, Champaign, IL 61820, USA; \\ Skidmore College, 815 North Broadway, Saratoga Springs, NY 12866, \\ USA
}

Received: 12 October 2018/Accepted: 16 April 2019

\begin{abstract}
This study examines the impact of firefighting intervention on occupant tenability to provide actionable guidance for selecting firefighting tactics that are based upon empirical rather than anecdotal evidence. Twelve fire experiments were conducted utilizing a full-sized residential structure to assess the impact of firefighting tactics on occupant exposure. Six groups of firefighters, recruited from fire departments throughout the country, participated in two experiments each. Two attack tactics were examined: (1) interior attack - water applied from the interior while a search team searched for simulated trapped occupants, and (2) transitional attack - exterior water application before transitioning to the interior while a search team searched for simulated trapped occupants. Gas concentration and temperature measurements were analyzed using a fractional effective dose (FED) approach to determine the impact of firefighter tactics on the exposure for potential trapped occupants. Water application by the fire attack teams resulted in a rapid drop in temperatures throughout the structure, followed shortly afterward by a decrease in the FED rate. There was no significant difference between the magnitude of the temperature decrease or the time until the inflection point in the FED curve between transitional attack and interior attack. As the removal time for the occupant increased, the toxic exposure to the occupant increased, despite the decreasing FED rate due to suppression. Occupant tenability analysis showed that the most threatened occupants are not always closest to the seat of the fire, while occupants near the fire but behind closed doors may have received a low exposure. As such, the results emphasized the need for rapid removal of occupants and coordination of suppression and ventilation tactics to limit toxic exposures.
\end{abstract}

Keywords: Firefighting, Tenability, Fire service, Fire dynamics

\footnotetext{
* Correspondence should be addressed to: Steve Kerber, E-mail: stephen.kerber@ul.com
} 


\section{Introduction}

A primary goal of firefighting is to extinguish fire in order to protect life and property. While this basic goal may seem straightforward to a civilian, the tactics used by the fire department to accomplish this goal may vary considerably. Based on an accumulating body of evidence, many fire departments are emphasizing the need to apply water to the fire as soon as possible to improve conditions inside the structure [1]. While there are many possible means for accomplishing rapid water application, two distinct approaches have been debated in recent years. One such approach is often called a "transitional attack" in which firefighters apply water through a window to initially suppress the fire before they enter the building to completely extinguish the fire and ensure there is no further fire growth. This approach contrasts the "interior attack" method that many firefighters have been taught, which is that it is best to initially enter the house through the front door with a charged hose line. The goal of this "interior" fire attack is to find the seat of the fire and extinguish it as soon as possible to protect potential occupants. Locating the seat of the fire from the exterior of a structure can be challenging if it is not venting from compartment windows, but several size up techniques can be employed to allow firefighters and fire officers to focus their efforts on rapid suppression coordinated with ventilation and search and rescue operations. An important aspect of the decision making process in determining one suppression technique versus the other is how employing such a tactic may impact tenability for trapped occupants.

Several previous studies have examined fire service tactics for their effectiveness and efficiency [2-8]. Each of these studies was focused on a specific fire service tactic and simulated those tactics in a controlled manner to examine the impact on the fire environment. In 2017, Traina et al. [9] examined the impact of firefighter transitional attack on occupants during a series of vertical ventilation experiments. They concluded that transitional attack was able to reduce the thermal fractional effective rate (FER) by $1 / 5$ in a ranch home geometry $60 \mathrm{~s}$ after water application. They did not examine interior attack and were not able to assess the impact of suppression on toxic gas exposure and FER. This study builds on these previous reports by including both interior attack and toxic gas measurements. Importantly, this study utilizes firefighters to perform the tasks, incorporating multiple operations and multiple firefighting teams as would occur in typical fireground operations. Additionally, by incorporating a search and rescue component valuable insights were gained on the impact of tenability of the simulated occupants as suppression, ventilation and search were performed to remove the simulated occupants from the hazardous environment.

Occupant tenability, which is related to the survivability of occupants in the fire environment, is a primary concern for any firefighting operation. Occupant tenability was estimated separately for two routes of exposure, temperature and gas concentration, using the fractional effective dose (FED) methodology from the SFPE Handbook [10]. FED relates to the probability of the conditions being nontenable for a certain percentage of the population through a lognormal distribu- 
tion. For reference, FED $=0.3$ is the criterion used to determine the time of incapacitation for susceptible individuals (young children, elderly, and/or unhealthy occupants) and corresponds to untenability for $11 \%$ of the population, and FED $=1.0$ is the value at which $50 \%$ of the population would experience untenable conditions. Untenability as a result of exposure to products of combustion is considered the point where the occupant would no longer be able to affect their own rescue. The method used to consider the time-dependent exposure of an occupant to toxic products of combustion is defined in Eq. 1.

$$
F E D_{\text {toxic }}=\left(F E D_{C O}+F E D_{H C N}\right) * v_{\mathrm{CO}_{2}}
$$

In Eq. 1, $\left(\mathrm{FED}_{\mathrm{CO}}\right)$ and $\left(\mathrm{FED}_{H C N}\right)$ are the fractional doses for carbon monoxide (CO) and hydrogen cyanide $(\mathrm{HCN})$, respectively. These terms are the fraction of an incapacitating dose at a discrete time step, $\Delta t$. A study conducted by Fent et al. [11] examined the fireground exposure of firefighters to various chemicals, including HCN. The study found that the interior and exterior teams (attack and outside vent) may be exposed to immediately dangerous to life and health (IDLH) concentrations of $\mathrm{HCN}$ if SCBA were not worn. Although $\mathrm{HCN}$ was not measured in these experiments and the tenability analysis does not include oxygen and irritant gas contributions, it is reasonable to assume that it would contribute to the toxic exposure of occupants trapped in the structure. Therefore, the results presented here are conservative. $\mathrm{CO}$ is often considered to be the most important asphyxiant gas that trapped occupants will encounter [10]. The expression for $\mathrm{FED}_{C O}$ is shown in Eq. 2, where $\phi$ is the $\mathrm{CO}$ concentration in parts per million and $d t$ is the time step, $\mathrm{V}$ is the volume of air breathed each minute, in liters, and $\mathrm{D}$ is the exposure dose, in percent $\mathrm{COHb}$, required for incapacitation.

$$
F E D C O=\int_{0}^{t} 3.317 * 10^{-5}[\phi C O]^{1.036}(V / D) d t
$$

Values of $\mathrm{V}$ and $\mathrm{D}$ vary depending on the level of work being conducted by the subject. The default case is often taken to be light work, which corresponds to $\mathrm{D}=30 \% \mathrm{COHb}$ and $\mathrm{V}=25 \mathrm{~L} / \mathrm{min}$. ISO 13571 [12] lists the uncertainty associated with the calculated FEDCO as $20 \%$. The uptake rate of $\mathrm{CO}$ and other products of combustion can vary considerably with $\mathrm{V}$, and is dependent on a number of factors, including hyperventilation due to $\mathrm{CO}_{2}$. This increase in respiration rate due to $\mathrm{CO}_{2}$ inhalation is accounted for in Eq. 1 by the hyperventilation factor, $v_{\mathrm{CO}_{2}}$. This factor is defined in Eq. 3, where $\phi_{\mathrm{CO}_{2}}$ is the mole fraction of $\mathrm{CO}_{2}$.

$$
v_{\mathrm{CO}_{2}}=\exp \left(\frac{0.1903\left(\exp \left(\phi_{\mathrm{CO}_{2}}\right)\right)+2.0004}{7.1}\right)
$$

ISO 13571 [12] lists the uncertainty associated with the calculated $v_{\mathrm{CO}_{2}}$ as $35 \%$. There is no FED criteria to conclusively predict lethality, as the pathology of toxic inhalation becomes complicated in the period between incapacitation and 
death. The incapacitating and lethal effects of $\mathrm{CO}$ inhalation are related to the carboxyhemoglobin $(\mathrm{COHb})$ level in the blood stream. Carboxyhemoglobin is formed when $\mathrm{CO}$ bonds with hemoglobin. Since hemoglobin has a higher affinity for $\mathrm{CO}$ than for oxygen $\left(\mathrm{O}_{2}\right)$, high $\mathrm{COHb}$ levels have an asphyxiating effect on vital organs, notably the brain. Incapacitating levels of $\mathrm{COHb}$ in the bloodstream are between $30 \%$ and $40 \%$ for the majority of the population, although susceptible populations may experience loss of consciousness at levels as low as $5 \%$. Death is predicted at $\mathrm{COHb}$ levels of $50 \%-70 \%$. Autopsy data indicates that survival is rare among fire occupants with $\mathrm{COHb}$ levels between $50 \%$ and $60 \%$, with $50 \% \mathrm{COHb}$ typically taken as the median lethal dose. Incapacitating levels of $\mathrm{COHb}$ are commonly found in surviving fire occupants [10]. Active subjects are more severely affected by $\mathrm{COHb}$ concentrations than sleeping subjects. Often, relatively minor increases in activity can result in the loss of consciousness to a previously sedentary subject.

A FED analysis was also conducted to examine the impact of thermal exposure to potential trapped occupants. The $\mathrm{FED}_{\text {temp }}$ tenability limit is commonly used as the expected onset of second degree burns. FED temp is composed of two components: a convective component and a radiative component, as shown in Eq. 4, where $t_{\text {conv }}$ is the time (minutes) to incapacitation due to convective heat transfer and $t_{\text {rad }}$ is the time (minutes) to incapacitation due to radiant heat transfer. Since $t_{\text {rad }}$ is a function of the heat flux from the gas layer, which was not measured, the radiative contribution was not considered in these experiments. Rather, the FED $_{\text {temp }}$ was calculated by considering the convective contribution, shown in Eq. 5, at an elevation of $0.9 \mathrm{~m}$ above the floor, representative of a person crawling on the floor (which will likely be higher than someone lying on the floor).

$$
\begin{aligned}
& F E D_{\text {temp }}=\int_{0}^{t}\left(1 / t_{\text {conv }}+1 / t_{\text {rad }}\right) \\
& F E D_{\text {conv }}=4.1 \times 10^{8} T^{-3.61}
\end{aligned}
$$

This series of experiments was also designed to examine the cardiovascular and carcinogenic risks of firefighting [13]. Analysis was done to characterize the thermal burden experienced by firefighters [14]. Measurements were made to characterize the area and personal air concentrations of combustion byproducts produced during controlled residential fires [15] and to determine what contaminants got onto the firefighters personal protective equipment and skin and how effective different decontamination procedures are [16]. This paper will focus on occupant survivability and the effectiveness of firefighter suppression (transitional attack and interior attack) and search and rescue tactics on occupant survivability. This will be accomplished by utilizing building gas temperature and gas concentration measurements placed close to two simulated occupants.

This analysis will focus primarily on comparing the relative magnitudes of FEDs in different locations within the structure, to compare the exposure to occu- 
pants that may have become trapped or incapacitated at those locations. Similarly, the FED rate of change can be used to assess the rate at which the exposure to a potential occupant would be improving or deteriorating. The FED itself can only increase or remain stagnant, it can never decrease, but a decreasing FED rate would indicate that an intervention is improving conditions. This can give insight into how the fire department actions are affecting the survivability of any occupants exposed to the environment.

\section{Methods}

\subsection{Subjects}

Subjects were recruited through a nationwide multimedia effort, along with a focus on a statewide network of firefighters who teach and train at the Illinois Fire Service Institute (IFSI). Forty $(\mathrm{n}=40)$ firefighters $(36 \mathrm{men}$, four women) from departments in Illinois, Georgia, Indiana, Ohio, South Dakota and Wisconsin participated in this study. On average, firefighters were $37.6 \pm 8.9$ years old, $1.80 \pm 0.08 \mathrm{~m}$ tall, weighed $89.8 \pm 14.5 \mathrm{~kg}$ and had an average body mass index of $27.6 \pm 3.4 \mathrm{~kg} / \mathrm{m}^{2}[14]$.

All subjects were required to have completed a medical evaluation consistent with National Fire Protection Association (NFPA) 1582 [17] in the 12 months prior to participation. An emphasis was placed on recruiting experienced firefighters who had up-to-date training, could complete the assigned tasks as directed, and were familiar with live-fire policies and procedures. Throughout the study protocol, all firefighters were required to wear their self-contained breathing apparatus (SCBA) prior to entering the structure. The research team supplied all personal protective equipment (PPE) for the subjects to enhance standardization and to ensure that all protective equipment adhered to NFPA standards.

The number of subjects recruited were necessary for statistical power required to examine the cardiovascular and carcinogenic exposure to the firefighters. Had the sole purpose been to examine occupant tenability we could have used the same four firefighters and had them accomplish the tasks in a repeatable manner. However, we were able to capture and analyze the variability of execution that could happen on the fireground everyday around the world where there are far fewer controls in place.

\subsection{Study Design}

A total of 12 experiments, each on separate days, were conducted. For each experiment, a team of 12 firefighters was deployed to suppress fires in a realistic firefighting experiment that involved a multiple-room fire (two separate bedrooms) in a $111 \mathrm{~m}^{2}$ residential structure. Each team of 12 firefighters worked in pairs to perform six different job assignments that included operations on the inside of the structure during active fire (fire attack and search and rescue), on the outside of the structure during active fire (command, pump operator and outside ventilation), and both inside and outside the structure after the fire had been suppressed 
(overhaul, during which firefighters searched for smoldering items and removed items from the structure). This manuscript will focus on those firefighters operating in the fire attack and search and rescue roles. These firefighters forced entry into the structure, suppressed the fire, searched for and removed two simulated occupants.

Experiments differed only in the tactics or methods used by the fire attack team: (a) traditional interior attack from the "unburned side" (advancement through the front door to extinguish the fire) and (b) transitional attack (water applied into the bedroom fires through an exterior window prior to advancing through the front door to extinguish the fire). The firefighters performed the same role using both methods. The tactics and tools used during these experiments are representative of those that may be used in the United States and may not be universally applicable.

In each experiment, the attack team of two firefighters approached the fireground at the time of dispatch, proceeded to the attack pumper, and deployed the hoseline with a smooth bore nozzle pumped at a pressure to flow approximately $570 \mathrm{lpm}$. The attack team was directed to execute either a transitional attack or an interior attack. For the interior attack experiments, the attack team deployed their hoseline to the front door of the structure, donned their SCBA, and made entry after the search team had simulated forcing entry. In the transitional attack experiments, the teams positioned their hoseline so that they could apply water to the bedroom on the A-side (front) of the structure. Once applying water to this window, the teams maneuvered their hoseline to the second window on the side of the structure, applied water to that window, before repositioning their hoseline to the front door to make entry. The duration of flow in each window varied between groups, and the average values are presented in Table 1.

The search team was delayed by $60 \mathrm{~s}$ following dispatch, to simulate companies arriving at different times. Upon arrival on the scene, the search team donned their SCBA masks and simulated forcing entry through a door on a training prop before entering the structure. The search team of two firefighters were instructed to search the structure beginning in the side of the house opposite the fire room (Fig. 1). The search team was not instructed how to search, but to use the techniques they are trained in and familiar with. As the teams searched, they found

\section{Table 1}

Times for Hose Deployment and Water Application

\begin{tabular}{lcc}
\hline Event & $\begin{array}{c}\text { Transitional attack } \\
\text { time (s) }\end{array}$ & $\begin{array}{c}\text { Interior attack } \\
\text { time (s) }\end{array}$ \\
\hline Time to firefighter interventions & $82 \pm 9$ & $127 \pm 11$ \\
Duration of water application in Bedroom A & $15 \pm 6$ & n.a. \\
Duration of water application in Bedroom B & $13 \pm 6$ & n.a. \\
Time between entry and flowing water on interior & $16 \pm 6$ & $10 \pm 6$ \\
\hline
\end{tabular}


the first simulated occupant, located in the corner of the dining room, propped against the far bedroom door. Once they removed this occupant, they continued their search pattern through the far closed bedroom, the kitchen, and the living room, before reaching the closed bedroom closer to the fire bedrooms, where the second simulated occupant was located.

\subsection{Study Protocol}

To ensure the fire experiments were conducted as repeatable as possible, a structure was designed and built to have interior finishes and features of a single family dwelling common in the United States and identical furnishings were used in each
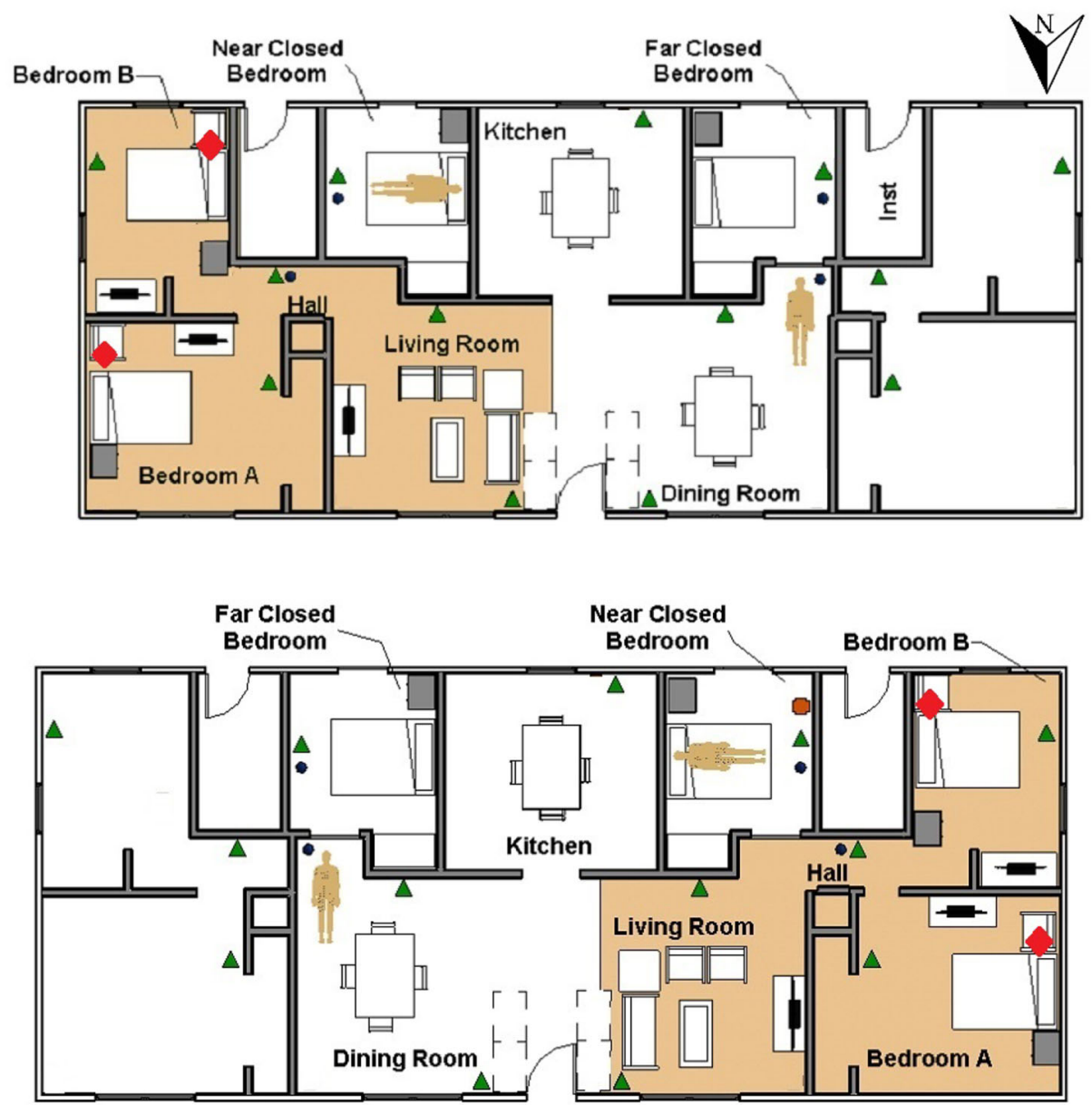

Figure 1. Layout of burn structure, location of occupants, and instrument locations for left (top) and right (bottom) layouts, key: triangle $=$ thermocouple array, circle $\mathbf{3}=$ gas concentration, diamond = ignition location. 
experiment. To ensure safety, specialized safety systems and hardened construction were employed. A residential architectural company designed the house to be representative of a home constructed in the mid-twentieth century with walls and doorways separating all of the rooms and $2.4 \mathrm{~m}$ ceilings. The home had an approximate floor area of $111 \mathrm{~m}^{2}$, with eight total rooms, including four bedrooms and one bathroom (closed off during experiments). Interior finishes in the burn rooms were protected by $15.9 \mathrm{~mm}$ Type $\mathrm{X}$ gypsum board [18] on the ceiling and $12.7 \mathrm{~mm}$ gypsum board on the walls. To maximize the use of the structure and minimize time between experiments, the house was mirrored so that there were two bedrooms on each side where the fires were ignited. During each experiment a temporary wall was constructed at the end of the hallway to isolate two bedrooms so that they could be repaired for the next experiment. The left and right layouts are shown in Fig. 1.

Furniture was acquired from a single source such that each room was furnished identically (same item, manufacturer, make model and layout of all furnishings) for all 12 experiments. The bedrooms where the fires were ignited, were furnished with a double bed (covered with a foam mattress topper, comforter and pillow), stuffed chair, side table, lamp, dresser and flat screen television. The floors were covered with polyurethane foam padding and polyester carpet. All other rooms of the structure were also furnished to provide obstacles commonly encountered by firefighters, but those furnishings were not involved in the fire. Figure 1 provides a plan view rendering of the structure to show the interior layout with furniture and floor coverings. The tan floor shows the carpet placement and the white floor shows the cement floor or simulated tile locations. Prior to ignition, all windows and doors were closed with the exception of the doors and windows of the two fire rooms (Bedrooms A and B).

Fires were ignited in the stuffed chair in Bedrooms A and B using a remote ignition device and a book of matches to create a small flaming ignition source. The flaming fire was allowed to grow until temperatures in the fire rooms reached levels determined to be near peak values based on pilot studies (i.e. room had 'flashed over') [1, 19]. For standardization purposes, dispatch was simulated when interior temperatures of both fire rooms exceeded $600^{\circ} \mathrm{C}$ at the ceiling $(4-5 \mathrm{~min}$ after ignition). The fire crews arrived to a ventilation limited fire with fire extending out of the windows in Bedroom A and B. Firefighters responded by walking approximately $16 \mathrm{~m}$ from the data collection bay to the front of the structure.

\subsection{Measures}

2.4.1. Building Temperature Measurements To assess fire dynamics throughout the experiments, measurements included gas temperature, gas concentrations, thermal imaging, and video recording. Detailed measurement locations can be found in Fig. 1 and [13]. Gas temperatures were measured with bare-bead, ChromelAlumel (type $\mathrm{K}$ ) thermocouples with a $0.5 \mathrm{~mm}$ nominal diameter. Thermocouple arrays were located in every room. The thermocouple locations in the living room, dining room, hallway, both closed bedrooms, and kitchen had an array of thermocouples with measurement locations of $0.3 \mathrm{~m}, 0.6 \mathrm{~m}, 0.9 \mathrm{~m}, 1.2 \mathrm{~m}, 1.5 \mathrm{~m}, 1.8 \mathrm{~m}$ and $2.1 \mathrm{~m}$ 
above the floor. The thermocouple locations in Bedroom A and Bedroom B had an array of thermocouples with measurement locations of $0.3 \mathrm{~m}, 0.9 \mathrm{~m}, 1.5 \mathrm{~m}$, and $2.1 \mathrm{~m}$ above the floor. All data was collected at a frequency of $1 \mathrm{~Hz}$.

2.4.2. Building Gas Concentration Measurements Ambient concentrations of $\mathrm{O}_{2}$, $\mathrm{CO}, \mathrm{CO}_{2}$ in the local environment were measured (OxyMat 6 and Ultramat 23 NDIR; Siemens) at $0.9 \mathrm{~m}$ from the floor inside and outside of the closed bedrooms. This measurement height corresponds with the height of the head adjacent to the simulated occupant sitting outside of the far bedroom and the simulated occupant lying on the bed in the near bedroom. This measurement height is also consistent with the height of the head of a potential occupant crawling to escape the fire. The uncertainty of the measured concentration is $1 \%$ of the maximum concentration measurement. The maximum concentrations measured were $5 \%$ for $\mathrm{CO}$ and $20 \%$ for $\mathrm{CO}_{2}$. All data was collected at a frequency of $1 \mathrm{~Hz}$.

2.4.3. Firefighter Intervention Measurements For each experiment, firefighter intervention was monitored and recorded utilizing standard video cameras placed outside and throughout the structure. Thermal imaging cameras were also placed inside the structure to examine firefighter movements and search and rescue techniques and tactics. Portable cameras were attached to the simulated occupants to qualitatively capture their exposure and movements from their locations to the outside of the structure as the firefighters rescued them.

\subsection{Occupant Tenability}

To estimate trapped occupant tenability, Eqs. 2 and 4 were numerically integrated using an Euler scheme and a discrete time step of $1 \mathrm{~Hz}$ using the building gas concentration measurements and building temperature measurements described above. The time to exceed the thresholds for all of the experiments in each house for both heat (only convection considered) and $\mathrm{CO} / \mathrm{CO}_{2}$ are calculated inside and outside of the near and far closed bedrooms. It should be noted that the values assume the simulated occupant was in that location for the duration of the experiment. It is again reinforced that these estimates may be considered lower bounds as additional thermal risks may be present from exposure to large radiant heat exposures or from the additive effects of exposure to a variety of different fireground gases such as HCN.

For any FED analysis, it is important to consider the large uncertainty associated with the measurements. Additionally, both heat exposure and toxic gas exposure will increase with increasing height in the structure. This fact is particularly important when considering an occupant walking out of the structure or a firefighter attempting to remove an occupant at standing height, which can result in higher FED values and lower times to untenability than at the $0.9 \mathrm{~m}$ height. However, the focus of this study is on the tenability at the crawling height of an occupant. 


\subsection{Statistical Analysis}

The combined uncertainty of Type $\mathrm{K}$ thermocouples is listed as $15 \%[20,21]$ and the combined uncertainty of the gas analyzers used in these experiments is $12 \%$. To assess the repeatability between experiments, the average temperatures at each occupant location in the $30 \mathrm{~s}$ prior to firefighter intervention were computed and compared to the uncertainty of these sensors.

A student's t-test was used to compare groups of variables, such as the method of attack, side of the structure, or group of firefighters. Because of the limited number of experiments, the sample sizes available to compare these variables were often quite small. Each of these analyses were performed with an alpha, or null value of 0.05 .

\section{Results}

\subsection{Building Temperature Measurements}

The $0.9 \mathrm{~m}$ above the floor (crawling height) temperature was used to assess the thermal exposure to which an occupant trapped at different locations within the structure may be subjected. The average temperature in the $30 \mathrm{~s}$ prior to firefighter intervention in the hallway, outside of the fire rooms was $320 \pm 64^{\circ} \mathrm{C}$. In the dining room, remote from the seat of the fire, the average temperature was $135 \pm 34^{\circ} \mathrm{C}$. The coefficients of variance were $20 \%$ and $25 \%$ for the hallway and dining room locations, respectively. These values are greater than the combined instrument uncertainty of $15 \%$, a difference which can partially be attributed to the wind. Since the test structure was not located in a controlled lab space, the presence or absence of wind could have an effect on flow paths within the structure. The wind conditions are shown in Table 2. Winds gusted as high as $7.3 \mathrm{~m} / \mathrm{s}$ during Experiment 5 however did not average more than $3.2 \mathrm{~m} / \mathrm{s}$ in any of the

\section{Table 2}

Wind Speed $(\mathrm{m} / \mathrm{s})$ and Direction

\begin{tabular}{lcccc}
\hline Experiment & Average & Minimum & Maximum & Direction \\
\hline Exp. 1 & 2.8 & 0.6 & 6.9 & $\mathrm{~W}$ \\
Exp. 2 & 2.6 & 0.2 & 6.0 & $\mathrm{SW}$ \\
Exp. 3 & 1.9 & 0.1 & 5.3 & $\mathrm{NE}$ \\
Exp. 4 & 0.9 & 0.0 & 2.0 & $\mathrm{SE}$ \\
Exp. 5 & 3.2 & 0.5 & 7.3 & $\mathrm{SW}$ \\
Exp. 6 & 1.5 & 0.0 & 5.3 & $\mathrm{NW}$ \\
Exp. 7 & 1.0 & 0.0 & 2.7 & $\mathrm{~W}$ \\
Exp. 8 & 1.6 & 0.0 & 5.9 & $\mathrm{NW}$ \\
Exp. 9 & 1.7 & 0.1 & 4.8 & $\mathrm{NW}$ \\
Exp. 10 & 2.0 & 0.0 & 5.2 & $\mathrm{SW}$ \\
Exp. 11 & 1.2 & 0.0 & 3.3 & $\mathrm{~W}$ \\
Exp. 12 & 1.2 & 3.2 & $\mathrm{~W}$ \\
\hline
\end{tabular}


experiments. The $0.9 \mathrm{~m}$ above the floor temperatures measured in the closed bedrooms were significantly lower than those measured in the areas of the structure open to the fire. The average temperature in the $30 \mathrm{~s}$ prior to intervention was $23 \pm 2^{\circ} \mathrm{C}$ in the near bedroom and $21 \pm 1^{\circ} \mathrm{C}$ in the far bedroom. The coefficient of variation for these sensors are $7.0 \%$ and $5.8 \%$ for the near and far bedrooms, respectively, less than the $15 \%$ combined uncertainty of the thermocouples. Representative temperature versus time graphs for each room and occupant locations are included in [13].

The high temperatures at $0.9 \mathrm{~m}$ above the floor in the open areas of the structure resulted in $\mathrm{FED}_{\text {temp }} \mathrm{s}$ in the hallway that exceeded the criteria for second degree burns. In the interior attack experiments, an $\mathrm{FED}_{\text {temp }}$ exceeding 1.0 was reached in $322 \pm 48 \mathrm{~s}$ and was reached in $322 \pm 34 \mathrm{~s}$ during the transitional attack experiments. For each attack method, this value was reached prior to firefighter intervention (442 $\pm 24 \mathrm{~s}$ for interior and $399 \pm 16 \mathrm{~s}$ for transitional). The maximum FEDs for each experiment and simulated occupant location are listed in Table 3. At the dining room simulated occupant location distant from the fire rooms, only Experiments 1 and 2 reached a FED temp in excess of 1.0. For the other experiments, the FED at the end of the experiment was $0.69 \pm .17$ for the interior attack experiments and $0.62 \pm .30$ for the transitional attack experiments.

The least severe thermal conditions were observed in the two closed bedrooms where temperatures at the time of firefighter intervention were lower in both locations than in the areas immediately outside of the closed door. Once firefighter intervention was initiated, whether from the interior or the exterior, there was no immediate effect on the temperatures or $\mathrm{FED}_{\text {temp }}$ within the room. In the experiments where the closed bedroom doors were opened for search and rescue, however, there was a corresponding temperature increase and $\mathrm{FED}_{\text {temp }}$ rate increase. Although opening the bedroom door to facilitate search often resulted in a measurable increase in the $\mathrm{FED}_{\text {temp }}$ rate, the total FED in both closed bedrooms

\section{Table 3}

Final FED

\begin{tabular}{lrccc}
\hline Experiment & Near hall & Dining room & Near closed bedroom & Far closed bedroom \\
\hline Exp. 1 & 7.92 & 1.28 & 0.02 & 0.01 \\
Exp. 2 & 12.02 & 3.25 & 0.04 & 0.04 \\
Exp. 3 & 9.69 & 0.87 & 0.04 & 0.03 \\
Exp. 4 & 35.43 & 0.56 & 0.02 & 0.03 \\
Exp. 5 & 33.25 & 0.76 & 0.07 & 0.03 \\
Exp. 6 & 8.86 & 0.24 & 0.03 & 0.02 \\
Exp. 7 & 16.64 & 0.68 & 0.03 & 0.02 \\
Exp. 8 & 9.15 & 0.29 & 0.02 & 0.03 \\
Exp. 9 & 39.07 & 0.43 & 0.04 & 0.03 \\
Exp. 10 & 1.96 & 0.43 & 0.03 & 0.03 \\
Exp. 11 & 19.76 & 0.86 & 0.04 & 0.03 \\
Exp. 12 & 7.97 & 0.71 & 0.03 & 0.04 \\
\hline
\end{tabular}


remained below 0.10 for both bedrooms and the $0.9 \mathrm{~m}$ above the floor temperature never exceeded $40^{\circ} \mathrm{C}$. Even the most severe thermal conditions within the bedrooms to which a trapped occupant would be subjected were less severe than those encountered in areas of the structure connected to the fire rooms.

\subsection{Building Gas Concentration Measurements}

At the time of firefighter intervention, the FED calculations varied considerably between experiments. At the near hallway location, just outside of the bedroom fires, the average FED value at the time of firefighter intervention was $1.06 \pm 0.96$. In the dining room location, next to the first simulated occupant, the average FED was $0.34 \pm 0.36$. The coefficients of variation were higher than those calculated for the building temperatures, and were $90 \%$ and $105 \%$ for the hallway and dining room, respectively. The variation that was noted in these measurements can be attributed to variations in the $\mathrm{CO}, \mathrm{CO}_{2}$, and $\mathrm{O}_{2}$ measurements. The variation in these measurements was greater than the uncertainty of the sensors. Additionally, because the FED equations presented in Eqs. 2 and 3 are exponential in nature, small measurement variations will result in larger variations in the FED calculation. Further, ISO 13571 [12] lists the uncertainty for the FED calculations as high as $35 \%$. In the closed bedrooms, the average FED value at the time of firefighter intervention was $0.007 \pm 0.005$.

Incapacitation levels were reached at $467 \pm 67 \mathrm{~s}$ and $453 \pm 31 \mathrm{~s}$ in the hallway gas sample location for the transitional and interior attacks, respectively. On average, the dining room occupant location reached incapacitating levels of exposure at a later time than the hallway, at $533 \pm 78 \mathrm{~s}$ and $618 \pm 136 \mathrm{~s}$ from ignition, for the transitional and interior attack, respectively. These times occur after the average firefighter intervention times $(390 \pm 16 \mathrm{~s}$ for transitional attack, $442 \pm 24 \mathrm{~s}$ for interior attack). Table 4 lists the maximum FEDs observed for each measurement location in each experiment. The average total FED values for the locations open to the fire rooms were $3.08 \pm 1.17$ and $2.31 \pm 1.03$ for the near hallway and dining room locations, respectively. These values were substantially higher than the FEDs recorded in the closed bedrooms, which were $0.63 \pm 0.58$ and $1.09 \pm 0.54$ for the near and far closed bedrooms, respectively. There was no significant difference between the two bedrooms $(p=0.22)$. This indicates that the closed bedroom door can provide an important reduction in an occupants exposure to products of combustion, which are noted in high concentrations low to the floor in the open areas of the house. Even in the near closed bedroom, the FED values measured behind the closed door are significantly lower $(p=0.005)$ than in the hallway immediately outside the bedroom. The near bedroom sample point was also significantly lower $(p=0.003)$ than the sample point located in the dining room, next to the simulated occupant. Representative gas concentration versus time graphs for each sample location are included in [13].

\subsection{Firefighter Intervention Measurements}

Each group of firefighters participated in one transitional attack experiment and one interior attack experiment. The only direction given to the groups performing 
Table 4

Final FED gas Values at Each Measurement Location

\begin{tabular}{lcccc}
\hline Experiment & Near hall & Dining room & Near closed bedroom & Far closed bedroom \\
\hline Exp. 1 & n.a & 4.62 & 0.51 & 0.19 \\
Exp. 2 & 3.31 & n.a & 0.45 & 1.08 \\
Exp. 3 & 4.13 & 3.26 & 1.64 & 0.55 \\
Exp. 4 & 1.85 & 1.00 & 0.14 & 2.38 \\
Exp. 5 & 3.58 & 1.39 & 1.89 & 1.13 \\
Exp. 6 & 2.27 & 1.68 & 0.43 & 1.04 \\
Exp. 7 & 4.19 & 2.44 & 0.83 & 0.83 \\
Exp. 8 & 1.91 & 1.75 & 0.62 & 1.43 \\
Exp. 9 & 2.86 & 1.90 & 0.31 & 1.06 \\
Exp. 10 & 1.26 & 1.59 & 0.09 & n.a \\
Exp. 11 & 5.42 & 3.50 & n.a & 1.17 \\
Exp. 12 & 3.05 & 2.27 & 0.07 & .a \\
\hline
\end{tabular}

n.a indicates a sensor malfunction at that location

these tasks was which method of attack to perform and which direction the search team should begin their search. A considerable amount of variation was noted in the time that the various groups took to complete fireground tasks such as hoseline deployment, hoseline advancement, and occupant location and removal. Table 5 lists the average times (with standard deviations) that the groups took to perform these actions. The least amount of variation (defined by the coefficient of variation), approximately $20 \%$, was noted in the hoseline deployment, which was defined as the time that the firefighter removed the hoseline from the fire engine to the time that the nozzle was "bled," ensuring that the attack team had a serviceable hoseline with water to the nozzle. The variability in the hoseline advancement, which was defined as the time from when the attack team entered the door to when they reached the hallway, was higher at $55 \%$. The highest variability was noted in the forcible entry task, which was $95 \%$.

The timeline of firefighter interventions varied with both the method of attack (transitional vs. interior) and the actions taken by the subjects during their execu-

\section{Table 5}

Times for Firefighting Tasks

\begin{tabular}{lcc}
\hline Task & $\begin{array}{c}\text { Mean time for task completion } \\
\pm \text { standard deviation (s) }\end{array}$ & $\begin{array}{c}\text { Coefficient of } \\
\text { variation (\%) }\end{array}$ \\
\hline Hoseline deployment & $79 \pm 16$ & 20 \\
Hoseline advancement & $29 \pm 16$ & 55 \\
Forcible entry & $22 \pm 21$ & 95 \\
Time to locate dining room occupant & $48 \pm 22$ & 35 \\
Time to remove dining room occupant & $37 \pm 13$ & 45 \\
Time to locate bedroom occupant & $140 \pm 54$ & 39 \\
Time to remove bedroom occupant & $60 \pm 38$ & 63 \\
\hline
\end{tabular}


tion of the fire attack (Table 1). From the time that the hoseline was pulled from the engine, the transitional attack resulted in significantly faster water application to the fire $(p<0.001)$ than the interior attack method. For the transitional attack, water was applied to the front bedroom in $82 \pm 9 \mathrm{~s}$, whereas in the interior attack experiments, entry to the structure was made in an average of $127 \pm 11 \mathrm{~s}$ after pulling the hoseline. Most of the interior attack teams utilized a "shut down and move" technique, where water would be applied from a stationary position, before advancing and repeating the maneuver. The teams applied water sometime between entering the structure and reaching the hallway. The first interior water application occurred $10 \pm 6 \mathrm{~s}$ following entry, and most teams applied water for $3 \pm 2 \mathrm{~s}$ on this initial application.

The average time between dispatch and entry for the search company was $204 \pm 24 \mathrm{~s}$ for the interior attack experiments and $227 \pm 29 \mathrm{~s}$ for the transitional attack experiments, which was not significantly different $(p=0.21)$. The longer average entry time in the transitional attack experiments was attributed to the additional time required to reposition the line to make entry in these experiments. In Experiments 1, 5, 7, and 8, the search teams missed the far closed bedroom, and the door was never opened. Table 6 shows the average times for the search team to find and remove each occupant during each fire attack method. While there is large variability in each of these times, method of attack (and its subsequent impacts on visibility and thermal conditions) was found to not have a significant difference on the time required to find the dining room occupant $(p=0.75)$ or the bedroom occupant $(p=0.32)$. Similarly, time required to remove the dining room occupant $(p=0.38)$ and bedroom occupant $(p=0.85)$ was not found to be significantly different between attack methods.

As the search company opened the doors to the near and far bedrooms in order to gain access and complete their search, the bedroom was no longer isolated from the rest of the structure. Out of the twelve experiments, eight search teams made entry into the far closed bedroom and searched it, and four passed over the bedroom, leaving the door closed and not searching. In the cases where the remote bedroom was opened and searched, an increase in FED rate was observed as products of combustion filled the room. For the four tests in which the door was not opened during the initial part of the search, this increase in FED rate was not observed. The peak FED rate calculated in the experiments where the search team opened the door $(0.0030 \pm 0.0010)$ was significantly higher $(p=0.003)$ com-

\section{Table 6}

\section{Times to Find and Remove Occupants}

\begin{tabular}{lcc}
\hline Event & Interior attack time (s) & Transitional attack time (s) \\
\hline Time to find dining room occupant & $36 \pm 15$ & $38 \pm 10$ \\
Time to remove dining room occupant & $42 \pm 21$ & $54 \pm 21$ \\
Time to find bedroom occupant & $218 \pm 62$ & $264 \pm 74$ \\
Time to remove bedroom occupant & $50 \pm 64$ & $56 \pm 21$ \\
\hline
\end{tabular}


pared to the peak FED rate for experiments where the door to the far closed bedroom was not opened and searched $(0.0010 \pm 0.0002)$. For the far closed bedroom, which was opened and searched earlier in the timeline of the experiment, opening the door resulted in an increase in the FED rate for any potential occupants located in the room.

The significant increase in FED rate following the opening of the door to the far bedroom was not observed in the near bedroom. The near bedroom door was opened in all twelve of the experiments. There was no significant difference between the maximum FED rate prior to and following the search team's entrance of the near closed bedroom. This is likely due to this room being opened later into the experiment after suppression had taken place and ventilation was occurring.

When considering the impact of suppression on occupant tenability within the structure, Experiments 3 (transitional) and 5 (interior) were treated as outliers, and neglected from the comparisons. In Experiment 3, the attack team applied water for only $4 \mathrm{~s}$ in each window, which allowed the fire to regrow by the time that the interior teams entered the structure. In Experiment 5, when the attack team reached the hallway, they did not have a sufficient length of hose to apply water into the fire rooms, reducing the effectiveness of the attack.

For the other experiments, after water was applied, whether from the interior or the exterior, the FED rate in open areas of the structure began to decrease. For the gas sample location in the hallway outside of the fire rooms, this inflection point occurred $43 \pm 28 \mathrm{~s}$ from the time that water was first applied for the transitional attack experiments and $35 \pm 30 \mathrm{~s}$ from the time that the attack team made entry for the interior attack experiments $(p=0.73)$. For the gas sample location in the dining room, this inflection point occurred $100 \pm 43 \mathrm{~s}$ from the time that water was first applied for the transitional attack experiments and $27 \pm 24$ s from the time that the attack team made entry for the interior attack experiments. This difference may not be statistically significant, but may be important in a real fire ground scenario. Apart from the two outliers experiments discussed previously, the FED rate did not increase at any time following water application. Thus, this FED rate inflection point can be taken as the time at which conditions would start to improve for occupants in an areas of the structure not isolated by a closed door or other barrier. For the near hallway position, there was no significant difference between attack methods, but for the dining room location, the interior attack method did improve conditions significantly more rapidly than the transitional attack method $(p=0.02)$. A possible reason for the more rapid improvement in the interior attack case is the ventilation that accompanies the opening of the front door and line advancement. As a flow path through the front door is established and fresh air enters the structure, products of combustion are displaced. The entrainment of fresh air, accompanied by the ongoing suppression, likely work in tandem to result in the improvement of conditions remote from the fire room. Table 1 shows that in the transitional attack experiments, water was applied to the fire approximately $45 \mathrm{~s}$ sooner after dispatch. The time from dispatch until the $\mathrm{FED}_{\text {gas }}$ rate inflection is $205 \pm 36 \mathrm{~s}$ for interior attack and $169 \pm$ 
$24 \mathrm{~s}$ for transitional attack, which is not a significant difference between the experiments $(p=0.14)$. Similarly, in the dining room sample location, the time from dispatch to the inflection point was $225 \pm 46 \mathrm{~s}$ for transitional attack and $192 \pm$ $12 \mathrm{~s}$ for interior attack, a difference which is also not significant $(p=0.27)$. Thus, while the interior attack resulted in a more rapid improvement in conditions in the dining room location from the time of water application, it also took longer from the time of dispatch to apply water to the fire, resulting in no significant difference when considering the two attack methods from a common time frame. There were a relatively small number of replicates and this difference may be important in practice even if not statistically significant.

Similarly, following the application of water, temperatures decreased throughout the structure at the $0.9 \mathrm{~m}$ elevations, and continued to decrease for the remainder of the experiment. Temperatures gradually approached ambient as spot fires were extinguished and ventilation was provided. In order to evaluate the effectiveness of the suppression mode, a $60 \mathrm{~s}$ window after the time of initial firefighter intervention was examined. This window encompasses the time required to position the hoseline to apply water to both bedroom fires, and captures the highest rate of temperature decrease following suppression. In the hallway between the fire rooms, this temperature decrease was $261 \pm 101^{\circ} \mathrm{C}$ for the transitional attack experiments and $313 \pm 69^{\circ} \mathrm{C}$ for the interior attack experiments, which was not significantly different between the two attack experiments $(p=0.42)$. The maximum rate of decrease, however, occurred more quickly $(p=0.004)$ after suppression for the transitional attack $(8 \pm 4 \mathrm{~s})$ than for the interior attack (33 $\pm 8 \mathrm{~s})$. This is likely because the limited visibility and geometry hinders the interior attack, an obstacle which is not present in the transitional attack.

The temperatures in the dining room area distant from the fire rooms also improved following suppression, although a larger decrease in temperature was noted for the interior attack than for the transitional attack. For the interior attack method, the temperature decrease was $103 \pm 29^{\circ} \mathrm{C}$ compared to a $30 \pm$ $16^{\circ} \mathrm{C}$ decrease for the transitional attack $(p=0.004)$. While this temperature difference is significant, the time between firefighter intervention and the time the minimum FED rate was observed $(29 \pm 19 \mathrm{~s}$ for transitional attack experiments and $13 \pm 8 \mathrm{~s}$ for the interior attack experiments), was not significant. Thus, while the time at which the temperature rate of change begins to decrease rapidly is not significantly different between the two attack methods, the magnitude of this rate difference is more pronounced for the interior attack method. Again, this is likely due to the fact that during the interior attack, the opening of the front door provides an immediate access route for fresh air to enter the structure and hot gases to exit, unlike the transitional experiment where there is no established inlet for fresh air other than the bidirectional flow path at the window until the team transitioned to the front door and opened it. The entrainment of fresh air, combined with the water application of the attack team, may be responsible for the more rapid decrease in FED rate and temperature. In the transitional attack, the opening of the front door was delayed until the attack team has repositioned, so the positive effects of suppression are delayed until ventilation is provided. 


\section{Discussion}

\subsection{Repeatability of Fireground Skills}

The variation in the times to task presented in Table 5 can be attributed to several factors. The age of the subjects, their level of experience conducting fireground operations, and the frequency and quality of their training can all affect the proficiency of firefighters in fireground skills. The variations in these times are often quite large when put into context on the fireground. For example, the slowest hoseline advancement group took 4.75 times longer to advance from the front door to the hallway than the fastest group. The minimum time that the search team breached the forcible entry prop was $5 \mathrm{~s}$, while the maximum time was $71 \mathrm{~s}$. The longest removal times for the dining room and bedroom occupants, respectively, were $93 \mathrm{~s}$ and $96 \mathrm{~s}$, whereas the shortest times were $13 \mathrm{~s}$ and $20 \mathrm{~s}$, respectively.

Although the actions of most teams adhered to a common timeline, several groups' actions deviated from this standard. In most of the transitional attack experiments, the attack team applied water to the front bedroom (Bedroom A), then moved to apply water to the rear bedroom (Bedroom B), before repositioning their line to the front door to make entry. In Experiment 6, however, after applying water to Bedroom B, the nozzle firefighter briefly applied water to Bedroom A for a second time before repositioning their hoseline to the front door and making entry. Incidentally, this attack team also became disoriented and advanced their line into the kitchen, rather than through the living room and down the hallway, taking $254 \mathrm{~s}$ to advance their line to the hallway. During this time, the temperatures within the fire rooms never rebounded, since their initial actions had suppressed the fire. Upon finding the occupants, the search teams in the majority of the experiments removed the simulated occupant out of the front door of the structure. In Experiment 4, however, the search team removed the bedroom occupant out the door in the rear of the bedroom to the exterior of the structure. This was the shortest removal time for that occupant (13 s).

Although firefighters of similar experience and training levels were sought for this study, there was a significant amount of variability in the amount of time required to complete fireground tasks. This variability between groups is compounded when operating in a dynamic fireground under poor visibility conditions. Therefore, when considering fireground operations such as search and rescue or fire attack, it must be understood that the same fire department, and indeed the same firefighters, are not arriving at every fire scene, and there is a significant amount of variability in how even common fireground tasks are performed. The scenarios presented here were realistic, yet relatively straightforward considering the involved compartments were visible to firefighters as they approached the scene. Additional delays and variability might be encountered if the fires had not vented from the structure and a search for the fire location were necessary. 


\subsection{Open Versus Isolated Areas}

The FED analysis indicated that the open areas of the structure, specifically the hallway and the dining room, experienced a maximum FED that was far higher than the maximum FEDs that were observed in the closed bedrooms that were isolated by residential hollow-core doors with no fire rating. Figure 2 provides a comparison between the maximum FEDs that were observed for the hallway and the near closed bedroom. The greatest thermal insult to a potential occupant was observed in the hallway close to the fire room, with the $\mathrm{FED}_{\text {temp }}$ at the end of the experiment ranging from nearly twice the incapacitating dose to almost 40 times the incapacitating dose. The dotted black line in Fig. 2 indicates the line of equivalence, the line where the gas exposure is equally severe to the temperature exposure. For an occupant in the near hallway location, all of the points lie above this equivalence line, the magnitude of the temperature exposure would be greater than the magnitude of the gas exposure. The high FEDs close to the fire room can be attributed to the high temperatures from the flows escaping the fire rooms, and the high concentration of products of combustion in the smoke near this area. The hallway was the only simulated occupant location where incapacitation due to temperature occurred before incapacitation due to gas concentration ( $322 \pm 44 \mathrm{~s}$ compared to $458 \pm 70 \mathrm{~s}$ ). When comparing the final $\mathrm{FED}_{\text {temp }}$ magnitudes, note that if the radiative contribution had been considered, the FED value

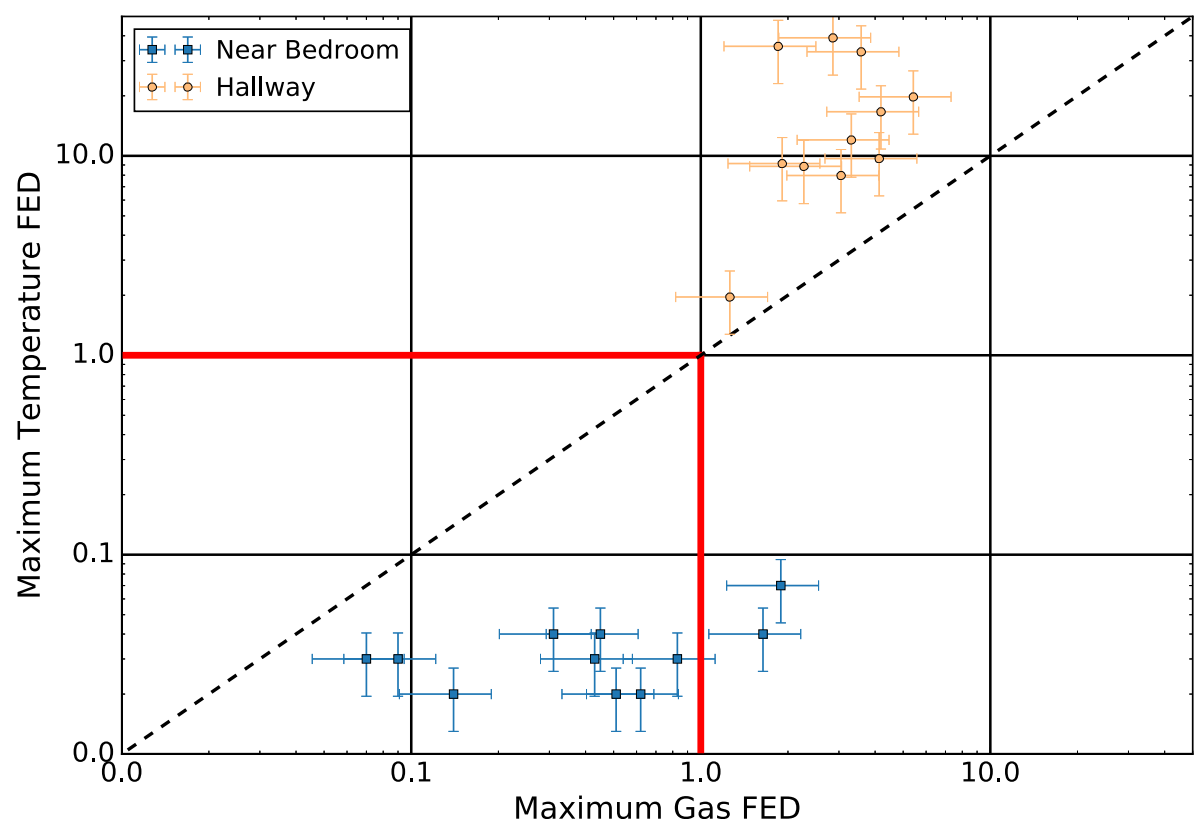

Figure 2. Maximum hallway and near bedroom FED values. FED gas is shown on $x$-axis and FED ${ }_{\text {temp }}$ is shown on y-axis. Red lines denote the FED at which incapacitation is expected for $50 \%$ of the population is expected (1.0). 
at the time of the end of the experiment would have been higher. This effect is likely to be much more significant in the hallway near the fire rooms, where radiant energy from the flames are likely to impact potential trapped occupants, compared to the opposite side of the structure.

The maximum $\mathrm{FED}_{\text {temp }}$ in areas remote from the fire room and in areas behind closed doors was dramatically lower than in the hallway outside of the fire rooms. Figure 3 compares the maximum FEDs calculated for each experiment in the dining room and far bedroom sample locations. In the dining room, the temperature tenability threshold was only exceeded in two experiments. In the closed bedrooms, none of the experiments exceeded a $\mathrm{FED}_{\text {temp }}$ of 0.07 , far less than the threshold of 0.3 , where $11 \%$ of the population would receive second degree burns. In each location other than the hallway outside the fire rooms, the $\mathrm{FED}_{\text {gas }}$ is significantly higher than the $\mathrm{FED}_{\text {temp }}$, indicating that the exposure to products of combustion is a greater threat than the thermal insult. In the open areas of the structure, both locations reached the gas tenability limit, with the exception of the dining room location in Experiment 4. In the closed bedrooms, the FEDs were lower than in open areas of the structure, and the FEDs were lowest in the areas where the door was kept closed the longest. The final FEDs were $1.09 \pm 0.54$ and $0.63 \pm 0.58$ for the far and near closed bedrooms, respectively. Additionally the

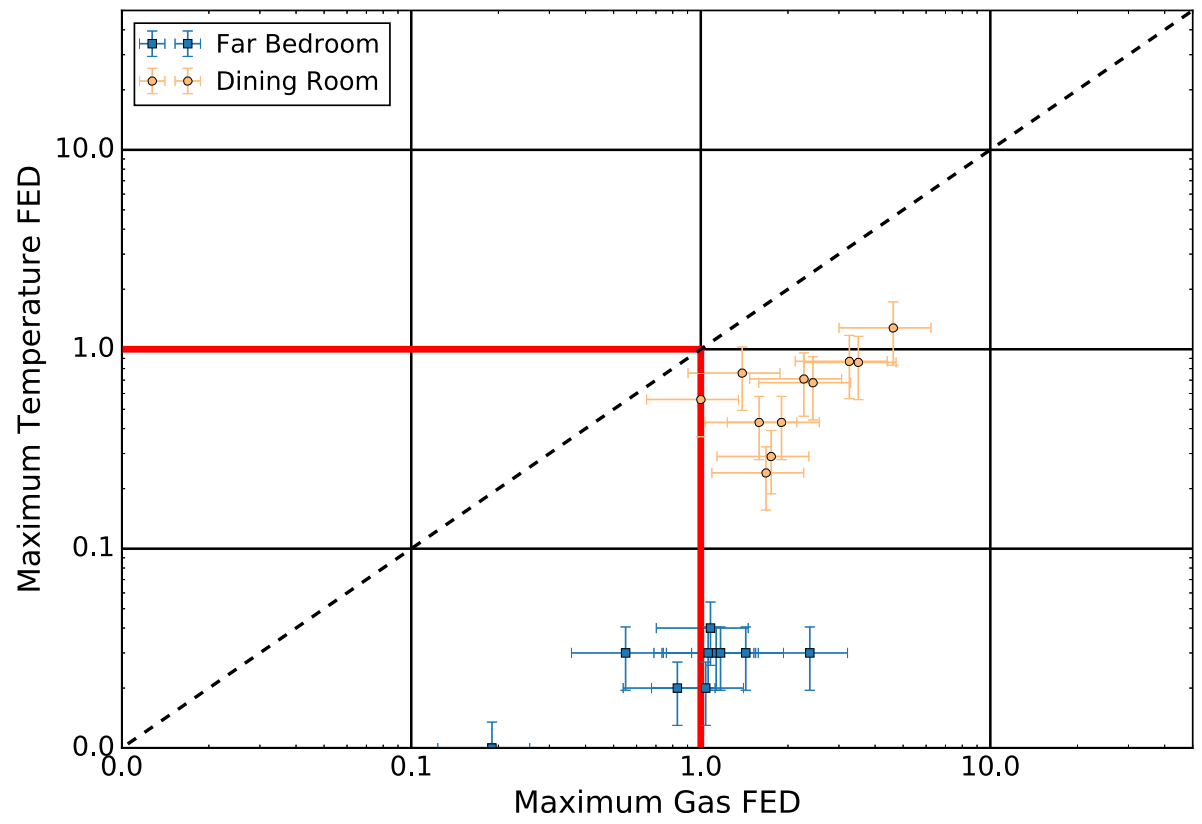

Figure 3. Maximum dining room and far bedroom FED values. FED gas is shown on $x$-axis and FED temp is shown on y-axis. Red lines denote the FED at which incapacitation is expected for $50 \%$ of the population is expected (1.0). 
FED rates in the open locations were higher than those observed in the closed areas.

The reason for the difference between the two bedrooms is likely due to the different points in the experimental timeline at which the door is opened and the room was searched. The near bedroom door was opened $113 \pm 52 \mathrm{~s}$ after the far bedroom. By the time that the search team reached the near bedroom, the smoke layer had already descended within the room to the gas sample point on top of the bed. Additionally, suppression had already occurred and smoke was venting from the area outside of the bedroom. In this case, the team that opened the door allowed the gases trapped behind the closed door to ventilate into the rest of the structure, improving conditions, as opposed to increasing the concentration of toxic gases. Thus, the effect of opening a closed door on the conditions behind it is dependent on the conditions in both rooms that the door connects.

\subsection{Search Methods and Simulated Occupant Removal}

The time to find and remove the simulated occupants in the dining room and the near closed bedroom varied more between the six groups of firefighters that participated in the experiment than between the attack methods, side of the structure, or whether the group had been through the experiment previously. There was no statistically significant difference in the times to locate or remove the occupants between the transitional attack method versus the interior attack method. This could indicate that there was not a sufficient improvement in visibility as a result of the early water application in the transitional attack experiments that aided the search team in finding the occupant more rapidly. While temperatures and FED rates dropped following initial exterior water application, as described in Sect. 3.3, the structure was still filled with optically dense smoke, indicated by zero visibility on cameras placed on the floor throughout the structure, at the time of firefighter entry. While suppression slows the production of products of combustion, the expulsion of products of combustion from the structure is a time-dependent process, and the rate at which smoke is exhausted and visibility is improved is related to the time of suppression, the methods of ventilation used, the wind speed and direction and the number, location and area of ventilation openings. While ventilation prior to suppression can increase the burning rate of the fire, and thus increase the production rate of toxic gases, ventilation closely coordinated with suppression is important for timely evacuation of products of combustion.

Common firefighting texts $[22,23]$ suggest that areas close to the suspected seat of the fire should be searched first, as occupants trapped in these areas are exposed to the greatest risk. In these experiments, occupants trapped in the near hallway are indeed at the greatest risk of thermal exposure, but this area is also the least likely location to find a tenable occupant. The other locations, while likely to reach untenable conditions for many occupants by the end of simulated activities, experienced significantly lower FEDs at the time of intervention. Figure 4 shows the FED values in the dining room and hallway at the time that the first occupant was found. These locations are approximately equidistant from the front door, and therefore can be used to compare if the search team first went 
towards the fire and found an occupant compared to a location on the opposite side of the structure. By searching away from the fire, the team may be more likely to find a viable occupant than when the search team first moves towards the fire. It is difficult to say conclusively whether the conditions at a certain point within a structure would be lethal, but the occupant found next to a post-flashover compartment fire has a higher likelihood of sustaining lethal burn injuries or incurring a lethal dose of toxic gases than one located remotely in the structure, as shown in Fig. 4. Occupants trapped close to the fire room should not be abandoned or neglected, but high priority should also be placed on the potential for viable occupants trapped remote from the seat of the fire that may also be in need of rapid removal. The search method employed by firefighters on the fireground is ultimately dependent on local policies and procedures and the circumstances of the specific incident.

It is important to note that the searches in these experiments were conducted in a single-story structure with a relatively simple geometry. Occupants were only required to be moved about $6 \mathrm{~m}$ to be extracted from the structure. If the floor plan were larger or more complicated, the times required to find and remove occupants likely would have been longer. Following suppression, the rate of gas concentration decrease was not as high as the rate of temperature decrease as described in Sect. 3.3. Although the FED rate was decreasing in the time that the

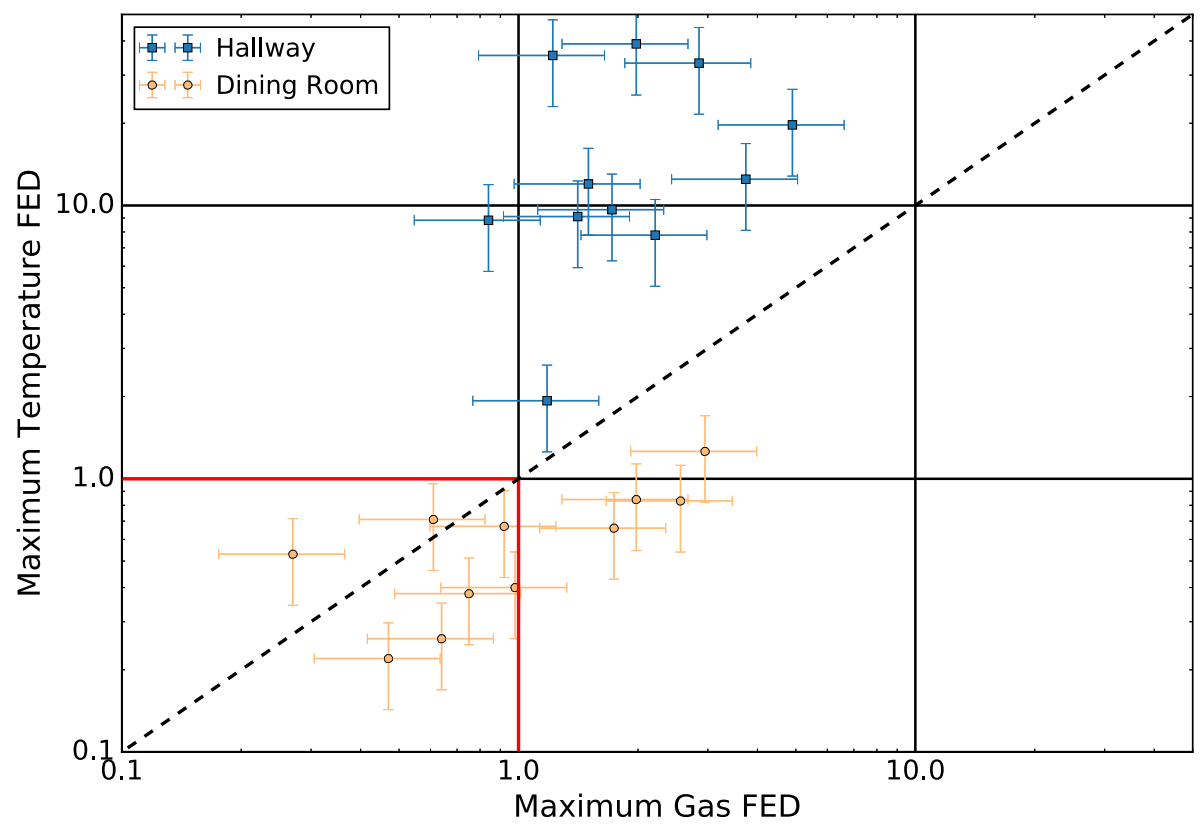

Figure 4. Near hallway versus dining room FED values at time of

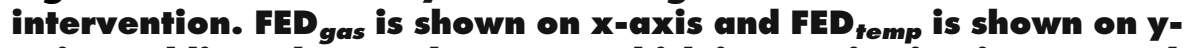
axis. Red lines denote the FED at which incapacitation is expected for $50 \%$ of the population is expected (1.0). 
search crew took to find and remove the occupants, the occupants would still be exposed to high concentrations of toxic gases. Because of the nature of the governing equations, even though the hazard was decreasing, the FED of any occupant would continue to increase until they were removed from the structure. This is demonstrated in Fig. 5, which plots the increase in FED toxicity from the time that the search crew made entry to the time that they located the dining room occupant. To control for variation in search crew effectiveness and variation in fire dynamics, the FED was calculated at the search time for all search groups and applied to each experiment. The increase in FED toxicity from the time of search team entry to the time of victim location was calculated for the 11 experiments with data for the dining room victim. The box and whisker plots show the distribution of the FED increase for each experiment, with the whiskers representing the FED increase corresponding to the maximum and minimum victim location times, the box corresponding to the middle quartile of increase, and the red line represents the FED increase for the median search time. The chart shows that as the time to find the simulated occupant increases, the tenability of the occupant is affected significantly. The time between the fastest and slowest victim removal was 46 seconds, yet in some experiments this time difference resulted in a $60 \%$

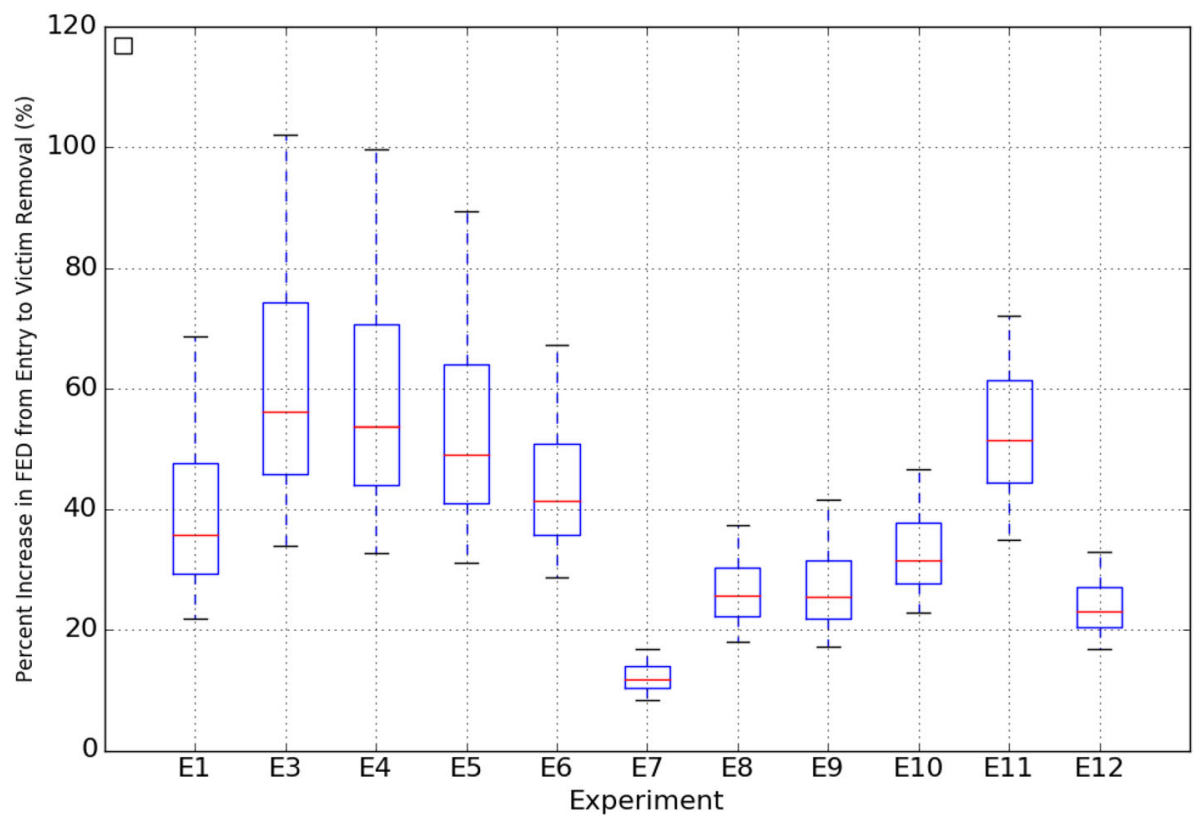

Figure 5. Relationship between occupant location time and $\%$ increase in FED between entry of search team and location of dining room occupant. Whiskers represent highest and lowest times to occupant found, red lines represent the FED increases of the middle two quartiles of the location times, and red line indicates FED increase corresponding to median location time. 
greater difference in FED increase. It follows that once the victim is found, the toxicity exposure to the victim will continue to increase during the removal process, as long as the occupant is still breathing. This emphasizes the importance of rapid removal of occupants located during the search in an effort to minimize the toxic exposure of these occupants.

In this series of experiments, most of the simulated occupants were removed from the structure out the front door from the location that they were found. The shortest occupant removal time, however, was observed in Experiment 4, where the search crew removed the bedroom occupant out of the rear door of the near closed bedroom. This removal method exposed the occupant to toxic gases for the shortest duration, but also avoided dragging the occupant through the hallway and living room, where the concentrations of products of combustion were higher than in the closed bedroom. Depending on the conditions within the structure, the location of the occupant within the structure, and the knowledge of the search company of alternative means of egress, the ideal path for occupant removal may be out of an opening separate from the one which the search team entered through, such as a rear or side door, or even through a window or down a ladder. This emphasizes the importance of situational awareness among the members of the search company and coordination of occupant removal.

\subsection{Attack Methods and Outliers}

With the exception of Experiment 3, the attack teams in the transitional attack experiments applied at least $9 \mathrm{~s}$ of water through the window of each fire room. In the majority of these experiments, the water application resulted in a temperature reduction throughout the structure, but most drastically in the fire rooms and hallway immediately connected to these rooms. The decrease continued until the attack team could advance their hoseline to the hallway for final suppression. The attack team in Experiment 3 directed their hose stream through the window for a shorter duration than the rest of the experiments, $4 \mathrm{~s}$ into Bedroom $\mathrm{A}$ and $3 \mathrm{~s}$ into Bedroom B. This short water application, combined with a delay in entry while the search team forced entry into the structure, allowed for a significant period of regrowth before the attack team reached the hallway to complete final extinguishment. The initial temperature decreases at the $0.9 \mathrm{~m}$ elevation in each of the fire rooms and the subsequent increases due to regrowth prior to final suppression are listed in Table 7. Following suppression, the $0.9 \mathrm{~m}$ temperatures decreased by $463^{\circ} \mathrm{C}$ in Bedroom A and by $235^{\circ} \mathrm{C}$ in Bedroom B. Because of the delay between the short initial attack and the final suppression when the attack team reached the hallway, the $0.9 \mathrm{~m}$ above the floor temperatures increased $269^{\circ} \mathrm{C}$ and $567^{\circ} \mathrm{C}$ in Bedrooms A and B, respectively. The temperatures in Bedroom B at the time that the attack team reached the end of the hallway were consistent with a post-flashover compartment fire. If the delay between initial and final suppression were longer, it is likely that conditions remote from the fire room would have started to deteriorate. This regrowth was not observed in the remainder of the transitional attack experiments, where the initial water application was longer. In many of these experiments, temperatures in the two fire rooms were still decreas- 


\section{Table 7}

Temperature Reduction and Subsequent Regrowth in Experiment 3

\begin{tabular}{lcccccc}
\hline Event & \multicolumn{2}{c}{ Experiment 3} & & \multicolumn{2}{c}{ Transitional attack average } \\
\cline { 2 - 3 } & $\begin{array}{c}\text { Bedroom A } \\
0.9 \mathrm{~m}(3 \mathrm{ft} .)\end{array}$ & $\begin{array}{c}\text { Bedroom B } \\
0.9 \mathrm{~m}(3 \mathrm{ft} .)\end{array}$ & & $\begin{array}{c}\text { Bedroom A } \\
0.9 \mathrm{~m}(3 \mathrm{ft} .)\end{array}$ & $\begin{array}{c}\text { Bedroom B } \\
0.9 \mathrm{~m}(3 \mathrm{ft} .)\end{array}$ \\
\hline $\begin{array}{c}\text { Temp. }\left({ }^{\circ} \mathrm{C}\right) \text { prior to exterior sup- } \\
\text { pression }\end{array}$ & 617 & 820 & & 542 & 759 \\
$\begin{array}{c}\text { Minimum temp. }\left({ }^{\circ} \mathrm{C}\right) \text { following } \\
\text { exterior suppression }\end{array}$ & 154 & 585 & & 91 & 162 \\
$\begin{array}{c}\text { Maximum temp. }\left({ }^{\circ} \mathrm{C}\right) \text { prior to } \\
\text { final, interior suppression }\end{array}$ & 282 & 1152 & & 104 & 175 \\
\hline
\end{tabular}

ing when the attack team reached the hallway. In the experiments where temperatures did begin to rebound, the increase was not of the same magnitude noted in Experiment 3. The average temperature prior to suppression, the average minimum temperature following suppression, and the average maximum temperature before the attack team reached the hallway for the other transitional attack experiments are listed in Table 7. The regrowth following the exterior attack in Experiment 3 resulted in a longer gap between suppression and the time at which the FED rate began to decrease. Thus, by failing to apply a sufficient amount of water during transitional attack, the effectiveness of the attack in improving conditions within the structure is limited.

Just as the duration of water application is important to the effectiveness of the attack, the location to which the water is applied is important. In the transitional attack experiments, the exterior water application occurred directly into the two fires rooms, resulting in a drastic reduction in temperatures when a sufficient amount of water was used. In the interior attacks, several groups applied water between the time they entered the front door and the time they reached the hallway. The poor visibility within the structure during this time makes it difficult to assess the effectiveness of these initial bursts of water, but the most effective cooling in the interior attack experiments occurred once the attack teams had reached the hallway, allowing them to apply water directly to the contents of the burning rooms. In one experiment, Experiment 5, the attack team did not apply any water until reaching the hallway. Upon reaching the hallway, an issue was encountered with the hose advancement, and the nozzle firefighter opened the nozzle, but was only able to apply water to the ceiling of the hallway for a brief period of time. The hose advancement issue was thereafter resolved, and the nozzle firefighter was once again able to advance and complete extinguishment. Prior to this final extinguishment, the temperature decreases in the area of the fire room were negligible, indicating that the water application was ineffective. The results of this experiment indicated that for effective and definitive suppression, water must be applied directly to burning fuels. 
In the transitional attack, water was applied earlier in the experimental timeline, resulting in a reduction in temperatures sooner than when compared to the interior attack experiments. After deploying their attack line, the teams conducting transitional experiments were able to immediately apply water to the fire, resulting in water application significantly faster than the interior attack groups and a reduction in temperatures sooner than when compared to the interior attack experiments. Once the interior attack groups deployed their hose line, they were often delayed while waiting for the search team to simulate forcing entry into the building. Despite the delay, the interior attack groups entered the structure faster $(174 \pm 10 \mathrm{~s})$ when compared to the transitional attack groups $(213 \pm 29 \mathrm{~s})$ $(p=0.02)$. Despite the early water application in the transitional attack experiments, there was no significant difference in the time at which the FED rate began to decrease between the two attack methods due to similar times to force entry and provide ventilation for clearing smoke.

\subsection{Limitations}

The equations used to compute the FEDs at each of the sample points for these experiment have a great deal of uncertainty associated with them, as high as $35 \%$. This high uncertainty, combined with the uncertainty of the measurements themselves, resulted in a large amount of scatter in the gas concentration data. Additionally, significant gas concentrations were not measured until the gas layer had descended to the point of the sample location, which in some experiments occurred later than others. A similarly large variation was not noted in the temperature measurements, indicating that although the thermal conditions within the structures were within a reasonable margin of uncertainty, the gas concentrations may be more susceptible to scatter. The gas sample locations in this series of experiments were fixed, which made accounting for the toxic exposure to simulated occupants during their removal from the structure difficult. Future work should attempt to assess how the occupants' toxic exposure changes during the removal process by using portable gas measurement techniques. Future studies may also focus on the impact of the fire size (including spreading outside the compartment(s) of origin), fire dynamics (vitiated, flaming, smoldering), multi-story structures, or the possibility that the occupant is located within the room of fire origin.

\section{Conclusions}

Utilizing a full sized single family residential structure with two fully involved compartments typical of room and contents fires, this study provides new data and insights into exposure conditions for trapped occupants and how variability in firefighting activities may affect tenability for those occupants. Consistent with fatality data from structure fires, occupants close to the origin of the fire sustained the most severe thermal exposures, likely reaching incapacitation from heat exposure prior to the exposure to products of combustion. These occupants also sustained the highest gas exposures of any simulated occupant location. Distant from this location but in areas open to the fire rooms, gas exposure levels reach FED 
values that were on average $169 \%$ higher than the thermal FED at this location but also $25 \%$ lower than those near the fire. The FEDs within the two closed bedrooms were found to be significantly lower than locations just outside of the closed door such that occupants trapped in the closed bedrooms would likely have been tenable well into the experiment, particularly if doors remained closed until rescue is affected.

Water application by the fire attack teams was associated with a rapid drop in temperatures throughout the structure, followed shortly afterward by a decrease in the FED rate. There was no significant difference between the magnitude of the temperature decrease or the time until the inflection point in the FED curve between transitional attack and interior attack. For the transitional attack experiments, water was applied to the fire significantly earlier in the experimental timeline than in the interior attack experiments, while in the interior attack experiments, the attack team made entry to the structure significantly sooner than in the transitional attack experiments. For both attack methods, significant improvements in interior conditions were observed following effective water application, while ineffective water application reduced or delayed the positive effects.

The coefficient of variations of the groups' times to execute various fireground actions ranged from $20 \%$ to $95 \%$. This emphasized the importance of training to develop proficiency in tasks such as hose advancement, forcible entry, and search techniques, as well as coordination between companies on the fireground to minimize miscommunication and improve efficiency. Importantly, as the removal time for the occupant increased, the toxic exposure to the occupant increased, despite the decreasing FED rate due to suppression. These results emphasized the need for rapid removal of occupants and coordinated ventilation with suppression to limit toxic exposures.

\section{Open Access}

This article is distributed under the terms of the Creative Commons Attribution 4.0 International License (http://creativecommons.org/licenses/by/4.0/), which permits unrestricted use, distribution, and reproduction in any medium, provided you give appropriate credit to the original author(s) and the source, provide a link to the Creative Commons license, and indicate if changes were made.

\section{References}

1. Kerber S (2013) Study of the effectiveness of fire service vertical ventilation and suppression tactics in single family homes. Report, Underwriters Laboratories, Northbrook, Illinois

2. Sardqvist S, Svensson S (2001) Fire tests in a large hall, using manually applied highand low-pressure water sprays. Fire Sci Technol 21(1):1-17

3. Svensson $S$ (2007) Investigating tactical patterns in a residential type structure. Fire Technol 43(3):195-212 
4. Kerber S (2013) Analysis of one and two-story single family home fire dynamics and the impact of firefighter horizontal ventilation. Fire Technol 49(4):857-889

5. Kerber S, Zevotek R (2014) Study of residential attic fire mitigation tactics and exterior fire spread hazards on fire fighter safety. Technical report, UL Firefighter Safety Research Institute, Columbia, MD

6. Zevotek R, Kerber S (2016) Study of the effectiveness of fire service positive pressure ventilation during fire attack in single family homes incorporating modern construction practices. Technical report, UL Firefighter Safety Research Institute, Columbia, MD

7. Zevotek R, Stakes K, Willi J (2018) Impact of fire attack utilizing interior and exterior streams on firefighter safety and occupant survival: full-scale experiments. Technical report, UL Firefighter Safety Research Institute, Columbia, MD

8. Madrzykowski D, Weinschenk C (2018) Understanding and fighting basement fires. Technical report, UL Firefighter Safety Research Institute, Columbia, MD

9. Traina N, Kerber S, Kyritsis DC, Horn GP (2017) Occupant tenability in single family homes: part II: impact of door control, vertical ventilation and water application. Fire Technol 53(4):1611-1640

10. Purser DA, McAllister JL (2016) SFPE handbook of fire protection engineering, chapter assessment of hazards to occupants from smoke, toxic gases and heat, 5th edn. Springer, New York

11. Fent K, Evans D, Babik K, Striley C, Bertke S, Kerber S, Smith D, Horn G (2017) Airbrone contaminants during controlled residential fires. Technical report, National Institute for Occupational Safety and Health, Cincinatti, $\mathrm{OH}$

12. International Organization for Standardization (ISO), ISO 13571 (2012) Life-threatening components of fire-guidelines for the estimation of time to compromised tenability in fires. International Organization for Standardization (ISO), Geneva

13. Horn GP, Kerber S, Fernhall B, Smith D (2016) Cardiovascular \& chemical exposure risks in modern firefighting: interim report. Technical report, Illinois Fire Service Institute

14. Horn GP, Kesler RM, Kerber S, Fent KW, Schroeder TJ, Scott WS, Fehling PC, Fernhall B, Smith DL (2017) Thermal response to firefighting activities in residential structure fires: impact of job assignment and suppression tactic. Ergonomics 61:404-419

15. Fent KW, Evans DE, Babik K, Striley C, Bertke S, Kerber S, Smith DL, Horn GP (2018) Airborne contaminants during controlled residential fires. J Occup Environ Hyg 15(5):399-412

16. Fent KW, Alexander B, Roberts J, Robertson S, Toennis C, Sammons D, Bertke S, Kerber S, Smith D, Horn G (2017) Contamination of firefighter personal protective equipment and skin and the effectiveness of decontamination procedures. J Occup Environ Hyg 14(10):801-814

17. National Fire Protection Association (2018) NFPA 1582: standard on comprehensive occupational medical program for Fire Departments, National Fire Protection Association, Quincy

18. ASTM International (2017) C1396, standard specification for gypsum board. ASTM, West Conshohocken

19. Kerber S (2012) Impact of ventilation on fire behavior in legacy and contemporary residential construction. Report, Underwriters Laboratories, Northbrook, IL

20. Blevins LG (1999) Behavior of bare and aspirated thermocouples in compartment fires. In: National heat transfer conference, 33rd proceedings, pp 15-17

21. Peacock RD, Mitler HE, Johnsson EL, Reneke PA, Blevins LG, Pitts WM, Braun E (1998) Temperature uncertainties for bare-bead and aspirated thermocouple measurements in fire environments. In: 14th meeting of the United States-Japan conference on 
development of natural resources (UJNR) panel on fire research and safety, University of Maryland, College Park, MD, USA

22. Mittendorf J (2011) Truck company operations, 2nd edn. PennWell, Tulsa

23. Norman J (2005) Fire officer's handbook of tactics, 4th edn. PennWell, Tulsa

Publisher's Note Springer Nature remains neutral with regard to jurisdictional claims in published maps and institutional affiliations. 